\title{
Escola Normal Rural e seu impresso estudantil
}

Rural Normal School and his student printing

\author{
Flávia Obino Corrêa Werle* \\ Lenir Marina Trindade de Sá Britto** \\ Gisele Nienov***
}

\section{Resumo}

Este texto discute o conteúdo do impresso estudantil $A$ Voz da Serra, periódico dos alunos da Escola Normal Rural La Salle, de Cerro Largo, Rio Grande do Sul, que foi publicado no período de 1946 a 1950. Conclusões indicam que, embora os variados títulos que o jornal recebeu, ao longo do tempo, acenassem para a especificidade rural da formação ministrada no curso, os temas nele tratados não davam prioridade ao mundo rural. Poucas eram as matérias que tematizavam essa realidade e formas de nela intervir. Assim, podemos levantar como hipótese de trabalho que, embora o objetivo da escola fosse a formação do professor para a zona rural, o veículo mantido pelo grêmio de alunos exprimia mais a socialização e a formação religiosa impressa na escola do que a formação para o campo e para a vida rural declarada no curso.

Palavras-Chave: Impressos Estudantis; Escola Rural; Formação do Professor Rural

\section{Abstract}

This text argues the content of the student journal A Voz da Serra, a students' journal of the La Salle Rural Normal School, Cerro Largo, Rio Grande do Sul, which has been published in the period from 1946 through 1950. Results indicate that, though the different headings the journal received along the times, it did not signal the rural specificity of education offered at the course; the issues treated by it did not give priority to the rural world. On the contrary, the themes that thematized this reality and the ways of intevention in them were very rare. Thus, we can raise the working hypothesis, that, although the objective of the school was the education of teachers for the rural zone, the vehicle maintained by the student gremium expressed rather socialization and religious formation, stressed in the school, than formation for the rural world and rural life declared in the course.

Keywords: Student Printings; Rural School; Rural Teacher Education

\footnotetext{
* Professora do Programa de Pós-Graduação em Educação da Universidade do Vale do Rio dos Sinos - UNISINOS (Porto Alegre/Brasil). flaviaobinowerle@pro.via-rs.com.br.

** Bolsista PIBIC - Graduanda em Pedagogia/UNISINOS.

*** BIC/FAPERGS - Graduanda em Pedagogia/UNISINOS.
} 


\section{Estudos ACERCA DE IMPRESSOS ESTUdANTIS}

Os impressos estudantis situam-se num vasto conjunto de meios de comunicação e publicação periódica referenciados à educação. Imprensa pedagógica e imprensa educacional são algumas das designações que tais fontes podem receber.

Para Nóvoa (1997, p. 13), imprensa educacional inclui um amplo espectro de publicações que revelam "as múltiplas facetas dos processos educativos numa perspectiva interna ao sistema de ensino (cursos, programas, currículos etc.), mas também no que diz respeito ao papel desempenhado pelas famílias e pelas diversas instâncias de socialização das crianças e dos jovens". Para esse autor, mesmo que a imprensa tenha caráter fugaz e imediato, seguindo a lógica de reação aos acontecimentos, constitui-se como um meio de afirmação de grupos e espaço de regulação coletiva. Tendo coordenado a elaboração de um repertório analítico da imprensa de educação e ensino em Portugal, afirma que a imprensa educacional possibilita a manifestação e a audição de "vozes" pouco consideradas em outros espaços sociais, tais como as que se apresentam na imprensa de iniciativa de estudantes (Nóvoa, 1997, p. 31). O autor, inclusive, exemplifica o modelo de ficha de análise de periódicos educacionais de seu projeto com o impresso estudantil $O$ Educador, elaborado por alunos de uma escola de formação de professores de Faro, Portugal.

Bastos (1997, p. 49) designa como imprensa periódica pedagógica jornais, boletins, revistas, magazines, independentemente do público a que se destinem e de que instância tenham tido origem. Assim, tanto publicações feitas para professores, ou destinadas a professores, como as elaboradas por alunos para os demais alunos, ou por professores para alunos, ou, ainda, mantidas pela hierarquia do sistema educacional, ou outras instituições ligadas à educação, tais como sindicatos, associações de classe, Igreja, partidos políticos, recebem essa designação. Para a autora, esse tipo de imprensa, ao captar e transformar acontecimentos, possibilita uma leitura do presente, uma articulação para o futuro e um registro do passado.

Como afirma Desaulniers (1997, p. 143, com base em Toressini), "ao produzir, divulgar e refazer constantemente informações [os impressos] 
acabam formando os indivíduos". A autora destaca, portanto, uma dimensão importante dos impressos: seu caráter formativo, além do de divulgação de idéias. Tal como Bastos, Desaulniers reitera que os impressos não reproduzem os fatos; ao contrário, retrabalham, modulam acontecimentos, crivam de nuances as informações e as fazem circular, disseminando-as em diversos espaços. Nóvoa (1997, p. 13), entretanto, destaca que a imprensa educacional produz uma "reflexão muito próxima do acontecimento", ou seja, o impresso testemunha fatos do contexto da época, registra opiniões e reações produzidas no imediato dos acontecimentos.

Imprensa educacional ou imprensa periódica pedagógica, o que caracteriza esse tipo de fonte é a possibilidade de (a) captar vozes ausentes em outros documentos, usualmente encontrados em instituições escolares; (b) ser um espaço em que acontecimentos locais e nacionais são captados, transformados e produzidos por reflexões, modulações e reinterpretações, e, ao mesmo tempo, "publicizados" em diferentes círculos sociais; e (c) constituir-se em instrumento de formação, afirmação e regulação coletiva.

A imprensa estudantil é um tipo de imprensa periódica educacional produzida em instituições escolares que atendem a essas características, ao fornecer indícios acerca da vida escolar, suas práticas, seus valores, seus ritos, suas crenças e seus símbolos. É uma imprensa constituída por grupos de alunos que, por curto período de tempo, estão na escola e que caracterizam, em seus escritos, ocorrências e imagens diretamente vinculadas aos atores ali presentes, e ao específico momento histórico institucional. Ou seja, é um espaço em que são expressados complexos processos de influência, de produção, de disseminação de opiniões e de informações acerca das relações entre estudantes, professores, direção, turmas de alunos, interações entre diferentes estabelecimentos escolares e com a comunidade externa à escola; bem como acerca da proposta formativa da escola, valores e objetivos compartilhados ou que devam ser reforçados, reafirmados.

Há duas linhas de abordagem de periódicos: uma centrada na análise interna do próprio impresso e sua produção, o ciclo de vida (duração, periodicidade, agentes responsáveis, colaboradores, recorrências e predominâncias temáticas); e outra que permite reconstruir o campo educacional e as disputas, os debates empreendidos e os grupos neles envolvidos (Catani; Sousa, 1999, p. 11, 15). As autoras, citando Pierre Caspard, afirmam que: "Um instrumento desse tipo não é 
metodologicamente neutro. As revistas analisadas não constituem um corpus em si que bastaria identificar e descrever. É necessário inventar esse corpus, isto é, tomar posição sobre uma acepção do campo educativo e manter em função dessa acepção as revistas pertinentes" (Catani; Sousa, 1999, p. 13 - grifo das autoras). No que se refere à produção impressa de iniciativas de alunos, elas reiteram que as

produções de alunos constituem um outro veio original a ser pesquisado, de vez que podem evidenciar aspectos da vida e da cultura escolar, até agora pouco analisados. Tal é o caso, por exemplo, das representações dos alunos acerca das atividades escolares e dos professores ou da própria vivência institucional e experiências de socialização. [...] A investigação acerca de tais materiais em muito pode contribuir para o enriquecimento da compreensão dos processos da vida escolar em termos da história do seu cotidiano, da ação dos atores educativos (alunos, pais e professores) e das próprias práticas pedagógicas, muitas vezes satirizadas nesses materiais. Trata-se de um dos poucos dispositivos capazes de tornar visíveis as vozes dos alunos na tradução de como aprendem e recriam configurações da situação de ensino. (Catani; Sousa, 1999, p. 17)

Catani e Sousa (1999, p. 20) organizaram uma tipologia de periódicos constituída de 16 categorias, dentre as quais citamos as mais próximas ao objeto de discussão deste artigo: "Boletins de associações discentes (grêmios, centros acadêmicos e associações de ex-alunos). Jornais escolares (realizados por iniciativa de escolas de ensino fundamental e médio).” O presente artigo tem como base empírica impressos estudantis da Escola Normal Rural La Salle, de Cerro Largo, Rio Grande do Sul, situados entre essas duas categorias. $\mathrm{Na}$ fase inicial do ciclo de vida, os impressos dessa escola se anunciavam como "órgão interno da escola". Depois, numa segunda fase, rearticulando sua identidade de impresso, passaram a se anunciar como "órgão interno dos alunos da escola".

Há pesquisadores, como Amaral, ${ }^{1}$ que não apenas destacam a importância do impresso estudantil, mas os situam como fonte relevante para a história das instituições escolares: "Os impressos estudantis,

1 Um projeto promissor sobre esse tema é "Imprensa estudantil em Pelotas", desenvolvido no Centro de Estudos e Investigações em História da Educação (CEIHE - FaE/UFPel), e impulsionado pelo conhecimento que as pesquisas de Amaral (1999, 2002, 2003, 2005) têm acumulado em relação ao tema. 
apresentados como fonte, podem representar uma possibilidade de recriação de um dos objetos intensamente abordados nas pesquisas em História da Educação, qual seja, as instituições escolares.” (2002, p. 120)

Neste trabalho concordamos que uma das possibilidades de abordagem da história das instituições escolares é a análise de impressos escolares que nelas tenham sido circulados ou tenham sido concebidos. Entendemos que tais impressos, tendo assumido a forma de revistas, de boletins ou de jornais, configuram espaços de ação/intervenção dos alunos, denotando, outrossim, a confirmação de projetos institucionais de formação, intenções de controle da ação do corpo discente e críticas destes aos seus colegas, a outros atores da escola e a processos institucionais. Em decorrência da quantidade e qualidade das informações obtidas acerca desses impressos, eles também podem auxiliar a configuração dos procedimentos de gestão de instituições escolares, as relações externas do estabelecimento, e neles encontrar relatos de ocorrências da instituição indisponíveis em outros espaços.

Pineda (2003) focalizou a Revista da Sociedade Cívica e Literária do Colégio Militar de Porto Alegre - Hyloea -, estudando a forma como o feminino era apresentado nela, desde a sua criação, em 1922, até o ano de 1938. A autora trabalhou com as categorias do cotidiano escolar, esportes, humor, sociedade, heróis, mulher e informes acerca da própria sociedade, analisando também o gênero das matérias (contos, poemas, crônicas), os tipos de colaboradores, as imagens e a comercialização da revista, bem como sua periodicidade, anunciantes, número de exemplares publicados e outras características de seu suporte material. Em pesquisa subseqüente, a autora está constituindo um repertório acerca da imprensa produzida por estudantes no Brasil, considerando o período 1900-1964, tendo listado 39 periódicos estudantis (Carra; Pineda, 2005).

Amaral (1999), estudando o Gymnasio Pelotense, destacou o papel da Sociedade Literária Grêmio dos Estudantes nos desenvolvimentos de conhecimentos literários, da capacidade retórica e comunicativa, de atitudes filantrópicas e da consciência política entre os estudantes, bem como na organização de festividades e de criação de peças teatrais. $\mathrm{O}$ periódico Estudante desse ginásio começou a circular em 1934 (Amaral, 2003, p. 214).

$\mathrm{Na}$ época, anos 30 do século XX, era usual as escolas fazerem permutas dos jornais e impressos estudantis, tanto é que um dos entrevistados de Amaral (2003, p. 215) refere que o Colégio Cruzeiro do 
Sul, em Porto Alegre, editava o jornal Pindorama, que inspirou os idealizadores e redatores do jornal Estudante do Gymnasio Pelotense. Registra-se que o Pelotense era um ginásio maçônico e pautado por ideais positivistas e anticlericais, e seu conteúdo era semelhante ao da escola católica que analisaremos a seguir. Isso ocorria, pelo menos, em matérias como poesias, piadas, contos, charadas, curiosidades, eventos esportivos, notícias da escola e do grêmio. Diferenciavam-se, entretanto, os impressos do Pelotense e da Escola Normal Rural pelo fato de que em "praticamente todas as edições do Estudante transparece a preocupação com a reflexão sobre aspectos sociopolíticos do país, que envolviam questões como a instrução, o trabalho e o papel da mocidade brasileira" (Amaral, 2003, p. 216), por conter uma seção de assuntos gramaticais e dúvidas da língua portuguesa e uma página do ex-aluno (Amaral, 2003, p. 219), elementos esses bem específicos dos impressos estudantis do Gymnasio Pelotense. Esses aspectos denotam a marca acadêmica e literária do impresso estudantil do Pelotense que o diferencia do impresso estudantil da Escola Normal Rural que a seguir será analisado.

Referindo-se ao periódico Ecos Gonzagueanos, impresso estudantil de uma outra escola da cidade de Pelotas - Colégio Gonzaga, um colégio católico masculino -, Amaral (2003) registra as diferentes designações que o impresso assumiu ao longo do tempo: Ensaio, O Pagode, O Cientista, Vida, O Alvorecer, O Estudante, O Gonzagueano. Identificamos também essa variação de nomes em nossa pesquisa para os impressos da Escola Normal Rural.

Diferentemente dos impressos do Gymnasio Pelotense, o Ecos Gonzagueanos tinha "censores" que acompanhavam e avaliavam as matérias que seriam publicadas, o "Irmão Henrique Miguel e o Prof. Rafael Alves Caldellas" (Amaral, 2003, p. 170). No caso das fontes encontradas na Escola Normal Rural, também há registros de professores que acompanhavam, supervisionando o que era publicado e, muitas vezes, colaborando com artigos.

Tal como no Hyloea - impresso estudantil do Colégio Militar (Pineda, 2003) -, Ecos Gonzagueanos registrava acontecimentos escolares: concursos literários, festas cívicas, religiosas e jogos, bem como uma seção de divertimentos incluindo fofocas, humorismo, charadas, adivinhações. Amaral identifica entre os colaboradores do Ecos Gonzagueanos ex-alunos, irmãos, pessoas ligadas à religião católica e a marcante presença de associações religiosas, como a Congregação Mariana (Amaral, 2003, 
p. 171). A referência a essa escola é importante neste trabalho, pois o Colégio Gonzaga passou dos jesuítas para os lassalistas, em 1926. Eram, pois, ambos, mantidos pela mesma ordem religiosa.

Do Ó (2003, p. 336), ao discutir o ensino liceal em Portugal, analisa "as pequenas publicações periódicas" que envolviam alunos, diretores ou redatores de impressos, ressaltando que, na primeira metade dos anos 30 do século XX, as autoridades educativas de Portugal regulavam esse tipo de imprensa. Reconheciam seu valor educativo, como entretenimento, como elemento vocacional e como forma de envolvimento dos estudantes na vida escolar, sem permitir, entretanto, que desviassem os estudantes do estudo regular de suas lições. Essas publicações, porém, não poderiam prescindir "de censura", o que devia ser feito "prudentemente pelos reitores” (Do Ó, 2003, p. 337). O diretor de cada escola exercia uma ação disciplinar decorrente "da sua convivência assídua e da sua participação activa e orientadora" nas associações estudantis (Do Ó, 2003, p. 339). Tais normas, datadas de 1933, recomendavam que jornais ou revistas estudantis deviam ter características estritamente escolares e serem confiadas a comissões formadas por alunos e, pelo menos, por um professor, não sendo permitido o tratamento de assuntos de política e o desrespeito a assuntos religiosos.

Portanto, há semelhanças entre os achados de diferentes autores quanto aos conteúdos de impressos estudantis. Destaca-se entre elas, por exemplo, a presença de um professor com função de censura na comissão de organização e redação dos impressos estudantis em colégios católicos. A alteração de designação dos impressos ao longo do tempo parece, da mesma forma, ser elemento comum a diversos estabelecimentos escolares que permitiam a feitura e circulação desse tipo de produção estudantil.

\section{Concepção de escola rural}

\section{e a Escola Normal Rural la Salle}

A política de educação para o mundo rural no Estado Novo (19371945) objetivava aproximar a escola de tarefas práticas à necessidades imediatas da população do campo. Acrescia-se a concepção de que educar era fixar e adaptar o homem à terra (Prado, 1995, p. 15). O ruralismo pedagógico (Prado, 2000, p. 50) apresentava-se como

uma tendência de pensamento articulada por alguns intelectuais que formularam idéias que já vinham sendo discutidas desde a década de 1920 e que resumidamente consistiam na defesa de uma escola 
adaptada e sempre referida aos interesses e necessidades hegemônicas no setor rural. Esse pensamento privilegiava o papel da escola na construção de um "homem novo", adaptado à nova realidade brasileira e de uma relação "homem rural/escola" pretensamente nova.

No Estado Novo as idéias de ruralismo pedagógico vinculavam-se a uma orientação pragmática, ou seja, o valor da escola rural se traduzia para além da ação educativa, em um trabalho cívico, patriótico e com finalidades econômicas. Se o objetivo da escola rural era valorizar, fixar o homem do campo ao seu meio, cabia ao professor primário rural divulgar a ideologia oficial: "ser um agente construtor e difusor da nova 'cultura política”" (Prado, 2000, p. 53). "Unindo cultura e política no mesmo campo das práticas materiais e simbólicas, criando-se o conceito de cultura política, buscava-se 'politizar' a vida do cidadão comum, torná-lo um soldado do Estado Novo.” (Prado, 2000, p. 52)

Portanto, o ruralismo pedagógico foi

uma tentativa de responder à "questão social" provocada pela inchação das cidades e incapacidade de absorção de toda a mãode-obra disponível pelo mercado de trabalho urbano. A essa ameaça permanente sentida pelos grupos dominantes, políticos e educadores tentavam ressaltar o "sentido rural da civilização brasileira" e reforçar os seus valores, a fim de fixar o homem à terra, o que acarretaria a necessidade de adaptar programas e currículos ao meio físico e à cultura rural. (Campos, 2001, p. 1, referindo Calazans)

A concepção de professor para zonas rurais foi construída nesse contexto, época em que se acreditava ser necessário criar "uma consciência agrícola contra o sentimento urbanista dominante" (Mennucci, 1934, p. 118). Para tanto, devia-se construir uma "escola nova", organizada sob a forma de internato, instalada em zona de campo, valorizando a educação rural e enfrentando o "flagelo urbanista". O professor rural devia ser entusiasta e conhecedor das lides agrícolas, portador de mentalidade e "perfil psicológico voltado para o campo, indiferente, senão mesmo quase antipático à cidade, tipo de homem que se proponha incentivar, através do prestígio de sua irradiação pessoal, o conforto do campo e a formação de uma consciência agrícola" (Mennucci, 1934, p. 122). A Escola Normal Rural devia seguir uma proposta diferenciada das escolas de formação de professores para zonas urbanas, contemplando três indispensáveis conhecimentos: agricultura, enfermagem e higiene. Além daqueles 
relacionados à inovação e ao incentivo do progresso no meio rural e de alfabetizar o homem do campo. O importante era formar um professor comprometido com o meio rural, consigo e com os demais; capaz de promover o desenvolvimento comunitário sustentado pelo lastro de conhecimentos relacionados à educação, higiene e agricultura, que lhe permitiriam interpretar as situações concretas com força transformadora. Um professor cujo saber e inteligência estivessem a serviço da ação e da mobilização de grupos rurais e que rearticulasse as dificuldades do meio, de forma a superá-las e reduzi-las. O professor rural deveria alcançar os objetivos de alfabetização, de formação higiênica, de amor e de capacidade de realização das atividades rurais. Para tanto, eram necessários três quadros distintos de professores: aqueles que se dedicassem ao ensino nas cidades, os que o fizesse nos meios rurais e os do ensino em zonas litorâneas (Mennucci, 1934, p. 189). Ou seja, os professores que atuassem em núcleos rurais deviam ser orientados para a agricultura, pecuária, indústrias agrícolas e para as pastoris, e aqueles que atuassem em zonas litorâneas deveriam voltar-se para "as fainas marítimas", a pesca e seus derivados. Nessa concepção rural de escola e professor, foram criadas as escolas normais rurais no Rio Grande do Sul na década de 1940.

A Escola Normal Rural La Salle, situada em Cerro Largo, mantida pelos Irmãos da Sociedade das Escolas Cristãs, constitui-se, nesse contexto, funcionando entre 1941 e 1972, tendo seu currículo organizado com o objetivo de formar professores para a zona rural. A escola era um internato que recebia alunos enviados pelas paróquias e prefeituras de municípios vizinhos com o objetivo de serem formados professores rurais, os quais, voltando para a sua região de origem, atuariam na educação e no desenvolvimento da agricultura. A escola promovia uma formação diversificada, fazendo com que os alunos, além de receberem estudos propedêuticos e de formação pedagógica, realizassem trabalhos em agricultura, se envolvessem com teatro, música, esportes e mantivessem um jornalzinho.

\section{O CORPUS EMPÍRICO E A METOdOLOGIA}

O artigo analisa impressos estudantis de uma escola de formação de professores para a zona rural, a Escola Normal Rural La Salle, de Cerro Largo. Tais impressos tinham objetivos literários, sendo, inicialmente, vinculados ao Grêmio Literário La Salle e depois à Associação de Alunos da escola, a qual não se declarava com objetivos 
exclusivamente literários, pois as atividades esportivas tinham grande relevância na escola e na comunidade, o que também transparecia no impresso estudantil.

Os impressos estudantis desta escola receberam designações diferenciadas ao longo do tempo: Crônicas, A Voz da Serra, O Normalista Rural, passando, a partir de 1956, a denominar-se O Ruralista, transformando-se em órgão oficial da UNEC, União Estudantil CerroLarguense, órgão de coordenação dos estudantes de Cerro Largo, e não apenas dos alunos da Escola Normal Rural La Salle. O total de 57 exemplares analisados foram localizados no Colégio Medianeira, nome atual do colégio lassalista, ${ }^{2}$ que manteve, entre 1941 e 1972, o Curso Normal Rural.

Este artigo foi elaborado a partir da consideração de 57 impressos estudantis da Escola Normal Rural La Salle, publicados entre 1946 e 1957, analisando especificamente cerca de metade deles. A metodologia de trabalho consistiu em análise realizada em dois tempos. Inicialmente, mapeou-se o conjunto de exemplares identificando a designação do jornal, o ano, o número, a data, o vínculo com o grêmio literário e respectiva presidência em exercício, os títulos das matérias e a publicidade veiculada. A segunda fase da análise contemplou o conteúdo das matérias, incluindo seu resumo e categorização conforme a temática contemplada.

O quadro a seguir especifica as diferentes designações, os exemplares que pudemos dispor para análise, bem como sua temporalidade. Não temos até o presente momento nenhuma informação acerca da quantidade total de números, sua distribuição e período em que realmente circulou.

2 Chegados em 1907 ao Brasil, indo diretamente para Porto Alegre e tendo já fundado uma dezena de estabelecimentos no Rio Grande do Sul, os lassalistas instalaram-se em Serro Azul. Isso ocorreu em 1935, quando assumiram a Escola Sagrada Família, paroquial, em funcionamento desde 1902. Na ocasião, foi assinado um convênio entre a SECSA (Sociedade Católica de Serro Azul) e os lassalistas, assegurando, em seus termos, dentre outras condições, o respeito à cultura e às tradições alemãs da localidade, com o compromisso de manter a continuidade do ensino em língua alemã. Para atender a necessidade de oferecer o ensino secundário aos filhos de colonos, foi fundado, em 1938, um internato e, em 1941, a Escola Normal Rural La Salle, em convênio com o governo do estado do Rio Grande do Sul. Esse curso Normal Rural funcionou até 1972. Os lassalistas também criaram, em 1959, nessa mesma cidade, o Ginásio Medianeira, transformado, no ano de 1969, em Colégio Medianeira. 
QUADRO 1

Impressos estudantis da Escola Normal Rural La Salle de Cerro Largo/RS e quantidades de exemplares analisados (1945-1957)

\begin{tabular}{|l|l|l|l|l|}
\hline \multicolumn{1}{|c|}{$\begin{array}{c}\text { Título do } \\
\text { impresso }\end{array}$} & \multicolumn{1}{|c|}{ Data } & $\begin{array}{l}\text { Anos dos } \\
\text { exemplares } \\
\text { disponíveis }\end{array}$ & \multicolumn{1}{|c|}{$\begin{array}{c}\text { Exemplares } \\
\text { disponíveis }\end{array}$} & \multicolumn{1}{|c|}{$\begin{array}{l}\text { Quantidade de } \\
\text { exemplares }\end{array}$} \\
\hline Crônicas & 1945 & & & \\
\hline Voz da Serra & $\begin{array}{l}1946-1950 \\
\text { Mensal }\end{array}$ & $\begin{array}{l}\text { Ano II ao ano } \\
\text { V }\end{array}$ & $\begin{array}{l}\text { Set. } 1946 \text { a } \\
\text { dez. 1949 }\end{array}$ & 26 \\
\hline $\begin{array}{l}\text { O Normalista } \\
\text { Rural }\end{array}$ & $\begin{array}{l}1953-1955 \\
\text { Mensal }\end{array}$ & $\begin{array}{l}\text { Ano VI ao } \\
\text { Ano VIII }\end{array}$ & 1953 a 1955 & 16 \\
\hline O Ruralista & $\begin{array}{l}1956-1957 \\
(?)\end{array}$ & $\begin{array}{l}\text { Ano IX ao } \\
\text { ano X }\end{array}$ & 1956 a 1957 & 15 \\
\hline \multicolumn{4}{|l}{ Total de impressos analisados } \\
\hline
\end{tabular}

Após várias leituras, focalizando o conteúdo dos impressos, identificamos categorias e articulamos em temáticas as matérias publicadas nos impressos. A análise do conteúdo de cada matéria dos impressos foi quantificada conforme demonstra o quadro a seguir.

\section{QUADRO 2}

Focos temáticos do conteúdo dos impressos estudantis da Escola Normal Rural La Salle De Cerro Largo/RS (1945-1957)

\begin{tabular}{|l|c|c|c|c|}
\hline & A Voz da Serra & O Normalista Rural & O Ruralista & Total \\
\hline Humorismo & 98 & 35 & 55 & 188 \\
\hline Social & 61 & 82 & 99 & 242 \\
\hline Religião & 41 & 37 & 30 & 108 \\
\hline Esporte & 23 & 44 & 41 & 108 \\
\hline Escolar & 58 & 41 & 84 & 183 \\
\hline Formação do & 10 & 5 & 1 & 16 \\
\hline Propaganda & 6 & 41 & 105 & 152 \\
\hline Ruralismo & 11 & 3 & 14 & 28 \\
\hline Outros & 22 & 13 & 2 & 37 \\
\hline Total & 330 & 331 & 431 & 1.092 \\
\hline
\end{tabular}

O projeto de pesquisa, ${ }^{3}$ no qual este texto se inclui, envolve também entrevistas com ex-alunos da Escola Normal Rural La Salle e, no que se refere ao tema dos impressos estudantis, o conteúdo de algumas dessas

3 Este texto é uma produção do projeto de pesquisa História das instituições escolares: escolas de formação de professores, apoiado pelo CNPq. 
entrevistas foi aproveitado em virtude da importância da informação e da contextualização de determinados detalhes que oferecem.

Este artigo discute o conteúdo e a forma do referido impresso, quando de sua designação $A$ Voz da Serra. Focalizamos especificamente esta fase do impresso estudantil por constituir-se num dos poucos veículos de comunicação escrita que circulavam na localidade naquele período. Embora muito simples e despretencioso, materialmente era um recurso inovador de comunicação de idéias na região. A importância do impresso da Escola Normal Rural La Salle é assinalada em entrevista de ex-aluno que explica por que, na segunda metade dos anos 1950, o jornal, nesse momento com a designação diferente, passa a ser impresso em gráfica, momento em que a cidade, recém-emancipada, passa a ter o seu jornal: "Eu sei que até essa época praticamente não existia uma imprensa local, até a emancipação não existia imprensa local. $\mathrm{O}$ único jornal era o dos irmãos aqui”, referindo-se ao Ruralista. Portanto, o impresso estudantil $A$ Voz da Serra, que circulou na segunda metade dos anos 1940, antes mesmo de a cidade ter o seu jornal geral, constituía-se em significativo veículo de comunicação, importante para toda a comunidade local.

\section{A Voz da SERra - características gerais DO IMPRESSO ESTUDANTIL}

O impresso estudantil nasceu na Escola Normal Rural La Salle, em 1945, com o nome de Crônicas, permanecendo assim apenas ao longo do ano de sua fundação, sendo posteriormente modificado para Voz da Serra.

O título Voz da Serra possivelmente decorre da relação com os diferentes nomes que Cerro Largo tomou ao longo do tempo. De acordo com Compagnoni (1980), por volta de 1902, a localidade situada ao norte do Rio Grande do Sul tinha o nome de Serro Azul, passando, em 1940, a designar-se Cerro Azul - tanto é que a Escola Normal Rural La Salle indica em documentos, junto ao seu nome, esta localização - e, a partir de 1945, passa a chamar-se, definitivamente, Cerro Largo.

Sob a designação de Voz da Serra, identificava-se como "órgão interno da escola", passando, em 1948, a se anunciar como "órgão interno dos alunos da escola", ocasião que teve seu título alterado para $A$ Voz da Serra. Portanto, passaram-se três anos, desde sua criação, até que o impresso foi definitivamente declarado como de autoria/origem/representação do corpo discente. Curiosamente, parece ter ele passado de uma fase mais 
informal (até 1948), de muita manifestação livre dos alunos, para uma fase mais formal, em que as matérias eram mais seguidamente assinadas, seu conteúdo de mais coloquial e descomprometido, torna-se mais informativo, mais "sério". Por informalidade referimos matérias que expressam camaradagem, crítica a colegas, relatos de acontecimentos cômicos, anedotas inspiradas nas ocorrências do dia-a-dia dos alunos na escola e o layout do impresso. Publicado mensalmente, o Voz da Serra, de aparência modesta, impresso em papel tipo jornal, era ilustrado com desenhos simples, contornos figurativos, muitos deles humorísticos, dentro das possibilidades que a tecnologia de mimeógrafo a tinta permitia. Possivelmente, os desenhos eram feitos a mão-livre, sem cópia ou formas, muito caricatamente. Os desenhos eram representações figuradas de pessoas, seus cacoetes, e dos acontecimentos, articulando no contexto dos impressos outras formas de expressão acerca das práticas e do imaginário escolar, uma forma alegórica e permeada de ironias.
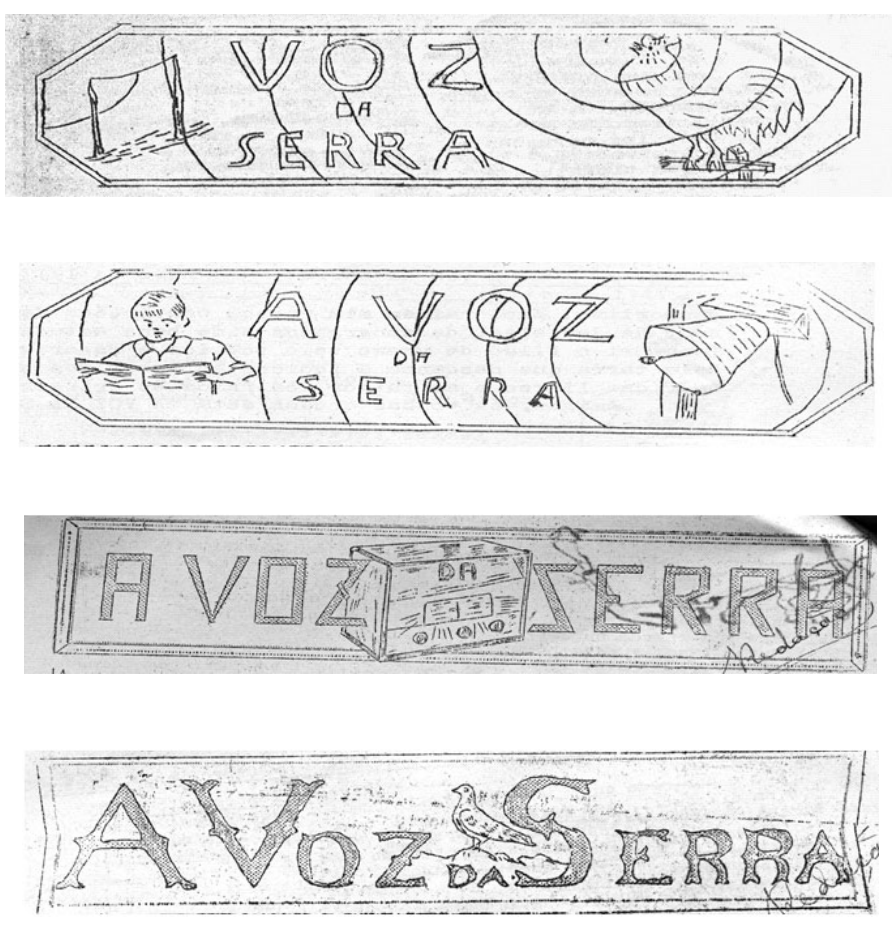

Figura 1 - Títulos do impresso estudantil da Escola Normal Rural La Salle. Exemplares de 1946, 1947 e 1948. 
O impresso de maio de 1949 indicava, dentre os que trabalharam como colaboradores, o nome do desenhista, o que indica a importância do mesmo para a confecção do impresso. Os desenhos eram geralmente acompanhados de observações, como se fossem breves legendas (Benito arrumando sua mala. São Luiz Gonzaga. Já vai cedo... - no exemplar do ano V, n. 1, abr. de 1949; Wodka. Sonhos dourados do Daniel para as férias; Lágrimas asininas após os exames, nada remedeiam; Tuba, rumo a São Borja - observações de três desenhos do exemplar ano IV, n. 9 e 10, dez. 1948).

O título do impresso, na página de abertura de cada número, recebeu, em diferentes momentos, grafia diferenciada; ora com o artigo "a", $A V$ oz da Serra, ora sem o mesmo. As imagens que acompanhavam o título relacionavam-se com sons, sendo variadas - um galo cantando, um menino lendo e um sino, um rádio, uma ave ou sem decoração (apenas o título).

O impresso veiculava muitos conteúdos humorísticos, ${ }^{4}$ como piadas, trocadilhos, diálogos, charadas com respostas no número posterior, rimas, anedotas acerca de situações divertidas ocorridas com os próprios alunos, torneios, relatos humorísticos de viagens, não descuidando de recomendações religiosas e textos de formação e voltados para a profissionalização e moralização de costumes.

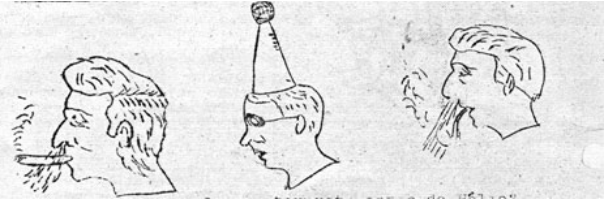

Quem interpreta estas do H..?

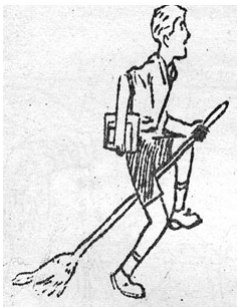

J.. vindo para a aula.

Figura 2 - Ilustrações humorísticas ( $A$ Voz da Serra). Escola Normal Rural La Salle, 1946.

Sousa (1997, p. 101), analisando a revista escolar Auxilium, do Colégio Santa Inês, publicada entre os anos 30 e 60 do século XX, refere dentre os conteúdos da revista concursos de problemas, adivinhações, perguntas, piadas, historinhas de fundo moral, charadas enigmáticas, desenhos que muito se aproximam do conteúdo que aqui estamos designando de humorísticos. Amaral e Silva (2005, p. 2, 3), analisando a revista científica, didática e literária do Clube Literário da Escola Complementar de Pelotas/RS, mencionam seções com perfil humorístico, incluindo charadas, divertimento e zombarias, um "caráter bem humorado, com brincadeiras dirigidas às alunas, não escapando os professores e professoras, nem mesmo o diretor e inspetor escolar". Amaral (2002, p. 123) reporta que muitos jornais estudantis foram eliminados dos arquivos dos estabelecimentos por sua "irreverência e crítica através, principalmente, de representações satíricas e caricaturizadas da sociedade, da escola de professores e de alunos". 
A estética e a organização não eram primorosas. Parecia relevante a ocupação integral dos espaços disponíveis no papel. ${ }^{5}$ Frases como as que seguem ocupavam os mínimos espaços entre matérias mais longas: " $\mathrm{O}$ sábio não diz tudo o que pensa mas pensa tudo o que diz", "Tudo o que eu sei é que eu nada sei", ou pequenas rimas: "a gente sofre na vida/ porque não sabe viver/ que faz da dor alegria/ vive sem nunca sofrer", "um homem para ser homem deve ter estes sinais, fazer muito, falar pouco e não se gabar jamais".

A partir de 1948 o impresso A Voz da Serra passa a ter maior dimensão e matérias predominantemente assinadas, maior organização, consistência de conteúdo e distribuição mais regular no papel. Há uma divisão de responsabilidades entre os alunos (matéria veiculada em 7 de abril de 1948) indicando o redator-chefe, redator da Congregação Mariana, Cronista da JEC, e autores das matérias "Tesoura da comadre", "Notas sociais", "Detetive dos externos", redator esportivo, que se constituíam em seções do $A$ Voz da Serra.

\section{OS ARTIGOS DE APRESENTAÇÃo dO IMPRESSO}

A apresentação do jornal de $1^{\circ}$ de maio de 1948 tem significativo conteúdo e imagem denotando identificação dos alunos com a escola e suas finalidades. Ilustra a primeira página um desenho do prédio da Escola Normal Rural La Salle. O texto refere os alunos formados em 1946 como disseminadores do trabalho da escola para "continuarem a espécie, para transmitir os caracteres da árvore-mãe: a Escola Normal Rural La Salle", citando o nome de cada um dos ex-alunos, a cidade de que eram naturais, onde estavam lecionando, qual a matrícula de sua escola, tipos de alunos atendidos, origem étnica dos mesmos, tipo de gestão que realizavam até o momento. A matéria é concluída com a totalização dos alunos matriculados na escola (132) e dos que nela se formaram professores rurais até o momento (17), bem como os municípios e distritos de origem. Era, portanto, um conteúdo que buscava o reforço dos objetivos da escola e a construção de um perfil profissional a ela associado discutido em Werle (2005).

Merece destaque também outro artigo de capa do $A$ Voz da Serra assinado pelo Irmão Geraldo, intitulado "O legislador da pedagogia

5 Sousa (1997, p. 106) faz registro semelhante "há pequenos textos, citações de pensamentos de autores, versos, etc, como estratégia de preenchimento de espaços em finais de páginas". 
moderna". As referências a João Batista de La Salle iniciam o texto que informa acerca da chegada dos irmãos ao Brasil e a sua obra em Cerro Largo, bem como o número de alunos atendidos pela congregação.

O Brasil é um país católico, mas as seitas protestantes e espíritas progridem e florescem rapidamente, graças à ignorância religiosa. A escola católica deve por barreiras a esta onda invasora, de erro. Fundar escolas católicas é cortar o mal pela raiz. Mais de 50 escolas abriram logo suas portas para, quando os Irmãos quisessem, entrar. Os operários são poucos. O povo católico deve ajudar nesta obra, com suas esmolas e orações a sustentar escolas pobres, a pagar os gastos de um ou mais formandos e assim contribuir para a salvação de muitos compatrícios abrindo-lhes escolas católicas. (Ir. Geraldo. "O legislador da pedagogia moderna", A Voz da Serra, ano IV, 1948, p. 1-2)

Não apenas a religiosidade era enaltecida nos artigos de abertura de cada impresso, mas também o civismo, a profissão de normalista rural, tanto referida em textos, destacando a importância da formação do professor, como nos que eram assinados por formandos e ex-alunos que falavam da vida profissional e de seus vínculos e reconhecimento para com a escola. A natureza formativa e moralizadora dessa parte dos impressos é também explicitada no artigo "O fundador das escolas normais", que ressalta a importância de São João Batista de La Salle como responsável por inovações pedagógicas: introdução do método simultâneo, instrução elementar obrigatória, pensionatos para jovens delinqüentes.

Em prova desta afirmativa basta recorrer à História da Pedagogia [...] em 1684 S. João B. de La Salle abria a primeira ESCOLA NORMAL (por ele denominada Seminário para professores rurais), isto é, 100 anos antes que o decreto de 3 de Brumário estabelecesse uma Escola Normal. Apenas em 1805 é que Pestalozzi abria outra Escola Normal na Suíça. A primeira ESCOLA NORMAL foi fundada em Reims, seguida pelas de La Fere e de Paris

O artigo de abertura do $A$ Voz da Serra, ano IV, n. 6, de setembro de 1948, intitulava-se "Semana da pátria" e destacava o patriotismo 6 de

$6 \quad$ "Os brasileiros devotaram-se com mais amor ao trabalho, sabendo que sua renúncia aos confortos seriam sacrifícios benéficos ao Brasil. Graças a estes nobres idealistas, o Brasil assumiu um lugar de projeção no cenário mundial, impondo-se como uma nação progressista e pacífica. 0 civismo que é a atitude moral, o procedimento honrado do verdadeiro patriota, zelando pelas tradições gloriosas que o passado nos outorgou, deve imperar no coração 
figuras intrépidas chamando os leitores ao exemplo, ao heroísmo, à luta pelos ideais.

O controle do comportamento ${ }^{7}$ e as normas severas de moralidade também tinham lugar nas primeiras páginas do $A$ Voz da Serra. Em novembro de 1949, no artigo de abertura, os bailes eram criticados como ocasião em que se cometem "pecados de impureza", em que os "sentimentos são arrastados à voluptuosidade", em que a "castidade morre", fazendo "corar uma criatura de bom senso".

Ex-alunos também figuravam como colaboradores eventuais no impresso que se divulgava como o "órgão interno dos alunos da Escola Normal Rural La Salle". No número 6, de outubro de 1949, do ano V, a abertura do periódico publicava uma carta de ex-aluno intitulada "Impressões sobre os grupos escolares rurais". Dentre os muitos comentários que o autor indica como um exemplo de líder da comunidade e de professor rural, registra quais os vencimentos iniciais, a importância do abono provisório, as recompensas de ser diretor, o pagamento dos que tinham seu horário desdobrado, as dificuldades enfrentadas nas distantes escolas primárias rurais. Como ex-aluno agradecido, apresentava seu reconhecimento aos professores da Escola Normal Rural La Salle e enviava saudações aos normalistas de seu tempo, que deveriam desempenhar seu trabalho nas zonas rurais com empenho e ciência. $\mathrm{O}$ ex-aluno descrevia também no artigo as condições de trabalho nas escolas rurais, demonstrando seu alinhamento com o perfil de professor especializado para a zona rural.

O Grupo Rural de Pratos foi criado em 1944, como simples Grupo Escolar e posteriormente foi classificado como Grupo Escolar Rural. Várias professoras passaram por este Grupo e todas elas arranjaram transferência por não ter-lhes sido possível, assimilar-se

de todo o brasileiro, principalmente nessa semana consagrada a reviver o maior feito patriótico que teve sua realização graças ao brio e coragem. [...] Todos devemos cumprir com nossos deveres patrióticos da melhor maneira possível: - o aluno aprofundando-se nas ciências, para assim elevar o nível cultural do Brasil; o agricultor, valorizando a terra com a semente de seu suor, contribui com um valioso quinhão para o engrandecimento da Pátria; a mulher enobrecendo o lar com seus sentimentos de caridade, deve ser o elo mais forte da harmonia familiar, que é base da unidade coletiva." (A Voz da Serra, ano IV, n. 6, set. 1948)

7 Com menos destaque, pois não constituía matéria de abertura do exemplar, mas com o mesmo objetivo de controle do comportamento do aluno fora da escola, o número de dezembro de 1948 registrava quatro normas para as férias, incluindo assistir missa, rezar, ler e lembrar-se que é aluno da Escola Normal Rural La Salle. 
ao meio, o qual é muito heterogêneo, mais do que possa imaginar, quer étnica ou religiosamente. [...] O povoado de Pratos fica numa curva do rio Uruguai, dista dois e meio quilômetros pelo lado oeste e três pelo lado norte do majestoso curso d'agua, divisa natural com a República da Argentina. [...] O Grupo Escolar Rural de Pratos, funciona, atualmente no centro do povoado, no lugar onde o movimento é maior, resultando constantes distrações dos alunos e martírio para os regentes de classe. Em face disso a direção do Grupo, num longo e documentado memorial, propôs a transferência do edifício ao senhor Secretário de Educação e Cultura, o qual mandou abrir concorrência pública e é de esperar, para o ano, que o Grupo funcione num local ermo, de terra boa e ubérrima, a fim de que todos os professores possam provar que são especializados para a zona rural. (AVoz da Serra, ano V, n. 6, out. 1949)

O trecho caracteriza também como se concebia a escola rural: um estabelecimento de ensino distanciado de zonas de maior concentração populacional, dotado de terreno para o desenvolvimento de atividades agrícolas.

Outra mensagem foi intitulada "A despedida da $4^{\mathrm{a}}$ turma de professores, 1949”. Nela, os seis formandos de 1949 elogiam e valorizam o colégio, os colegas, a hospitalidade de Cerro Largo e suas instituições.

Os temas de abertura, mais longos do que os demais, traziam uma mensagem de formação, destacando o patrono da congregação lassalista, personagens exemplares, enaltecendo a escola, o civismo, a pátria, a profissionalização, o compromisso do professor. Cuidavam eles, portanto, da mensagem formativa desse veículo de expressão/comunicação dos alunos da escola e com isso a construção de uma identidade articulada a valores morais, religiosos e de amor à terra, nacionalismo.

\section{Seções Religiosas}

O controle de comportamento e a formação religiosa estavam presentes sistematicamente em duas seções, a da "Juventude católica" e a da "Congregação Mariana", nas quais registravam-se acontecimentos, reuniões ocorridas e novos candidatos dessas associações. Visitas de bispos e de padres de outras cidades, conferências, eram também informadas nesses espaços. Em inúmeros espaços do $A$ Voz da Serra e de diferentes formas era relembrada a importância da devoção à Virgem Maria e às festas religiosas, datas comemorativas de santos e a importância de rezar. 


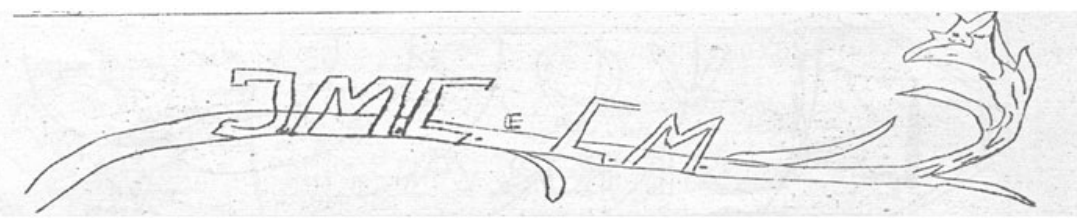

Figura 3 - llustração da seção religiosa do impresso estudantil $A$ Voz da Serra, da Escola Normal Rural La Salle.

Portanto, esse impresso estudantil assumia, ao lado de um cunho moralista, uma dimensão de propagação do cristianismo. No desenho de um lírio, identificamos a seção da Congregação Mariana, seu simbolismo de pureza e castidade.

\section{Permutas: 0 IMPResso como VisibiLIDAde da escola}

O contato com impressos estudantis de outras escolas era também registrado no $A$ Voz da Serra. No exemplar de maio de 1949, por exemplo, há agradecimentos pelo recebimento do Ginasiano de escola de Minas Gerais e do Amigo de La Salle da Associação dos Ex-alunos do Externato São Luiz, de Canoas. Não apenas o recebimento de outros impressos era registrado, mas menções elogiosas quanto ao próprio $A$ Voz da Serra eram matérias de publicação. Nessas ocasiões a redação se manifestava como responsável pelo impresso e envaidecia-se pelos elogios, embora não assinasse os agradecimentos.

Esses registros acentuam e convergem para a idéia de impressos estudantis como veículo de comunicação para além do estabelecimento escolar que o edita, "diferentemente do livro, a imprensa periódica é uma mídia interativa na orientação da qual os leitores participam de um modo ou de outro, quer escrevendo para ela, quer assinando-a ou deixando de fazê-lo" (Catani; Sousa, 1999, p. 14). No caso do impresso estudantil da Escola Normal Rural La Salle constata-se que ele desempenhava um papel de mediação entre a escola e a comunidade local e regional e dava visibilidade para a escola e para o tema da escola rural.

\section{AUtoria E CENSURA NOS IMPRESSOS ESTUDANTIS}

A presidência e outros cargos de direção do impresso eram alternados entre alunos dos últimos anos do Curso Normal Rural, conforme informa um entrevistado. Essa estratégia assegurava continuidade do trabalho e linha editorial, sendo também um espaço de formação. 
Aqui é toda a minha turma Vicente Miguel Soarez, Nei Shedler, Jaci Klein, primeiro secretário. José Golfetto, mora em Santa Maria. Então é que existia um grêmio, o grêmio literário, então era tradição que a direção pertencia pras duas séries [...] a última série assumia a presidência, era a responsável, mas já tinha uma turma da série anterior para dar continuidade ao trabalho. No outro ano aqueles assumiam.

A autoria dos conteúdos veiculados no impresso estudantil não era, ao que parece, campo de disputa. Ao contrário, os autores preferencialmente permaneciam no anonimato, o que pode sugerir a pouca legitimidade atribuída aos impressos estudantis pela administração e hierarquia da escola. A assinatura das matérias inexistia, havendo pseudônimos, ou apenas as iniciais do nome e do sobrenome, ou o último sobrenome para marcar a autoria. O pseudônimo proporcionava o anonimato, o que era adequado em caso de matérias que manifestavam críticas, ironias ou de tom sarcástico. Assim, por exemplo, um acontecimento presenciado por um ou poucos perdia o caráter de ocorrência privada quando nas páginas do impresso estudantil. Algo acontecido entre dois alunos ou presenciado por poucos colegas, ao ser divulgado pelo impresso estudantil, para toda a escola, talvez desgostasse os envolvidos, e a ausência de autoria evitava certos constrangimentos e, provavelmente, acertos de contas. Nesse caso, o pseudônimo preservava o autor de explicar e justificar a publicação de tais acontecimentos, de "publicizá-los" para toda a escola e para fora dela. O autor da notícia, anedota, conto, observação escrita tinha assegurado, sob o pseudônimo, a possibilidade de não ser notado, conhecido como autor.

É possível identificar duas fases de vida do $A$ Voz da Serra, como anunciamos anteriormente. A primeira, em que era órgão interno da escola, quase um ensaio descontraído de impresso estudantil, pleno de informalidade. $\mathrm{Na}$ segunda fase, o impresso se autoproclamava como "órgão interno dos alunos", quando ocorre um discreto direcionamento para os alunos assumirem mais a autoria do impresso. Nesse momento, entretanto, ainda quem escreve e fala é um "abstrato de alunos", mais do que uma diretoria de grêmio literário ou estudantil, com cargos desempenhados por indivíduos com nome e sobrenomes.

Como as matérias não eram assinadas, ou o eram por um pseudônimo, é difícil identificar quando apenas alunos e quando professores colaboravam. 
Ex-alunos também colaboravam, como informa um antigo aluno da escola:

Até tenho lá em casa, eu tenho um exemplar de 10 de janeiro de 1957, mas aí eu já não era mais, eu já era professor, onde tá publicado um artigo que eu escrevi sobre a inauguração da viação férrea aqui, com a visita do Juscelino Kubischek, esse eu tenho guardado lá em casa.

A dúvida quanto a quem eram os colaboradores, entretanto, nos números 9 e 10, do ano IV, é dissipada quando a redação expressa agradecimentos aos leitores e à dedicação dos colaboradores "onde se destacam: o Revmo. Ir. Celso, Ir. Geraldo e outros”. Alguns Irmãos colaboravam no impresso na seção "Ortografia" ou com alguns textos de abertura de cada número. A dificuldade de identificar os colaboradores de impressos estudantis, já registrada por Pineda (2003), motivou, no impresso que estamos estudando, a matéria a seguir transcrita:

Muita gente reclama ao receber alguma cacetada em $A$ Voz da Serra e nada pode fazer porque aparece no fim do artigo um pseudônimo qualquer, ou umas simples iniciais. À medida que obtivermos autorização para isso, revelaremos aos leitores os portadores dos pseudônimos (i. e., nomes falsos) nossos colaboradores de ontem e de hoje. Dr. Xisto = Pedro Ari Pinto de Andrade (sócio-fundador). Rei Negro, Saci Pererê, L. Bastos = Vidalêncio L. de Camargo. Onilecram $=$ Marcelino Cassol. D.H.S. $=($ Dr. Das Hervas Santas $)$ Irã Antonio Rosa. Ranzinz a = Paulo V. Aquino. Cláudio Vici = Antônio V. Grando. (A Voz da Serra, dez.1948)

Portanto, um mesmo autor tinha vários pseudônimos, e o uso de iniciais não guardava relação direta com as letras do nome do autor da matéria, encobrindo-o. Pode-se levantar a hipótese de que fazia parte do jogo de colaborar com o impresso escolar, o fato de passar incólume, não identificado como crítico ou, quem sabe, delator de algum fato. $\mathrm{O}$ anonimato da autoria, comum nos impressos estudantis prevenia represálias, evitava que os autores tivessem que dar explicações para além do espaço do impresso, prevenindo, talvez, reprimendas e castigos da hierarquia escolar, caso ocorressem críticas mais fortes ou em direção não permitida. Por outro lado, verifica-se nessa matéria a sensibilidade do impresso para com a opinião e pedidos de seus leitores.

\section{Elementos conclusivos - A Voz da Serra}

A Escola Normal Rural La Salle, criada em 1941, era uma escola masculina cujo currículo voltava-se para um específico perfil de professor: um professor especialmente preparado para a zona rural. Em fevereiro de 
1958 foi criada a Escola Primária Rural, anexa à Escola Normal Rural La Salle, local onde eram realizadas as práticas de ensino e estágios necessários à formação docente. Entretanto, bem antes da criação da escola anexa, a escola normal mantinha com regularidade um impresso estudantil. Propunha a formação de professores para o ambiente rural e a fidelidade à fé cristã, acrescentando à formação do professor a do catequista e a capacidade de expressão escrita e comunicação com a comunidade, para o que o impresso estudantil contribuía.

Pela análise do impresso escolar $A$ Voz da Serra, pode-se afirmar que o perfil de professor rural era intencionado na instituição e reforçado nos conteúdos veiculados nesse impresso, que se tornava um instrumento para os objetivos da escola, da religião e da formação do professor rural. Por certo os impressos estudantis eram uma estratégia para manter os alunos ocupados de forma ordenada e de prover mais um meio de fortalecer as propostas formativas da escola: religiosidade, emulação e o disciplinamento. Os impressos estudantis, e como tal $A$ Voz da Serra, desempenhavam esse papel até pelo destaque a jogos e esportes, pela divulgação de equipes vencedoras de torneios e premiação, valorizando os grupos vencedores. Por outro lado, o impresso promovia a boa relação entre alunos e professores, divulgava os aniversariantes de um e de outro segmento escolar, anunciava o nascimento de filhos de professores, bem como o casamento de algum docente, ou mesmo falecimentos. O impresso promovia temas relacionados com a saúde e a higiene, mas não de forma predominante. A formação religiosa, ao contrário, estava sempre presente em suas páginas. Portanto, a socialização era atendida, pois havia espaços para divulgar os aniversariantes, desenvolvendo maneiras polidas de interação pela referência aos "onomásticos", a festas escolares, excursões. A formação moral era também assegurada por meio de artigos/editoriais que traziam "uma lição moralizante" de cunho normativo.

Entretanto, não se pode dizer que a mensagem principal do impresso fosse a divulgação de conhecimentos relacionados ao mundo rural e à nítida propagação do ruralismo pedagógico, mas uma formação do professor de orientação católica, moralizante e um instrumento de construção de identidades de alunos, ex-alunos com a escola e sua proposta formativa.

Discutimos neste artigo a importância e as características da imprensa educacional, ou imprensa periódica pedagógica, como fonte para a história das instituições escolares, focalizando, neste amplo conjunto de recursos, os impressos estudantis. A relevância de tais impressos como 
documentos que trazem indicativos para a história institucional decorre de seu conteúdo, de seus autores, de seus censores, dos espaços em que circulam, dos temas que lhes são interditos e das abordagens e ênfases que oferecem aos acontecimentos. Os impressos estudantis expressam temporalidades, interações, ajudam a descortinar um contexto, selecionam e mapeiam fatos, reúnem, num conjunto, dados da instituição. Assim ocorreu com o impresso $A$ Voz da Serra. Sendo um impresso estudantil de colégio lassalista, nele também figurou, com destaque, o fundador da congregação que dirigia o colégio, a marca da religiosidade presente na instituição, assim como a preocupação moralizante e disciplinadora da formação oferecida na escola. Por outro lado, o perfil de aluno fazia-se presente em matérias de autoria de ex-alunos que eram chamados a colaborar e a dar depoimentos da vida profissional, formando e modelando os leitores, inspirando-os também a serem profissionais. A vida rural se fazia presente em suas páginas, assim como as temporalidades do internato e das férias, que representavam volta para o lar e retomada de hábitos muitas vezes ausentes da vida de estudante de colégio interno. Em conclusão, a análise de coleções de impressos estudantis oferece uma visão panorâmica das interações ocorridas no estabelecimento e de sua proposta formativa, constituindo-se, sem sombra de dúvida, em importante fonte para a história das instituições escolares.

\section{Referências Bibliográficas}

AMARAL, Giana Lange do. Gatos pelados x galinhas gordas: desdobramentos da educação laica e da educação católica na cidade de Pelotas (décadas de 1930 a 1960). Tese (Doutorado em Educação). Porto Alegre, Faculdade de Educação, UFRGS, 2003.

AMARAL, Giana Lange do. O Gymnasio Pelotense e a maçonaria: uma face da História da Educação em Pelotas. Pelotas: Seiva/UFPel, 1999.

AMARAL, Giana Lange do. Os impressos estudantis em investigações da cultura escolar nas pesquisas histórico-institucionais. História da Educação, ASPHE/UFPel, n. 11, p. 117-130, abr. 2002.

AMARAL, Giana; SILVA, Daiani Santos da. Aspectos da cultura escolar veiculados pelo impresso estudantil "Complementarista" da Escola Complementar de Pelotas/RS. In: XI ENCONTRO SUL-RIO-GRANDENSE DE PESQUISADORES EM HISTÓRIA DA EDUCAÇÃO. São Leopoldo/ Unisinos: ASPHE/UFPel, ago. 2005. CD-ROM. 8 p. 
BASTOS, Maria Helena Câmara. As revistas pedagógicas e a atualização do professor: a Revista do Ensino do Rio Grande do Sul (1951-1992). In: CATANI, Denice Bárbara; BASTOS, Maria Helena Câmara. Educação em revista: a imprensa periódica e a história da educação. São Paulo: Escrituras, 1997. p. 47-76.

CAMPOS, Eliane Pinheiro Medeiros. O ensino rural: uma discussão de especificidades. In: REUNIÃO ANUAL DA ANPED, 24. Anais... GT5, Estado e Política Educacional, out. 2001.

CARRA, Patrícia R. Augusto; PINEDA, Silvana Schuler. Mapeando a imprensa estudantil no Brasil de 1900 a 1964: um projeto de pesquisa em história da educação em uma escola de educação básica. In: XI ENCONTRO SUL-RIOGRANDENSE DE PESQUISADORES EM HISTÓRIA DA EDUCAÇÃO. São Leopoldo/Unisinos: ASPHE/UFPel, ago. 2005. CD-ROM. p. 272-274.

CATANI, Denice Bárbara; SOUSA, Cynthia Pereira de (Org.). Imprensa periódica educacional paulista (1890-1996): catálogo. São Paulo: Plêiade, 1999.

CATANI, Denice Bárbara; VICENTINI, Paula Perin, LUGLI; Rosário S. Genta. O movimento dos professores e a organização da categoria profissional: estudo a partir da Imprensa Periódica Educacional. In: CATANI, Denice Bárbara; BASTOS, Maria Helena Câmara. Educação em revista: a imprensa periódica e a história da educação. São Paulo: Escrituras, 1997. p. 77-92.

COMPAGNONI, Ivo Carlos. História dos irmãos lassalistas no Brasil. Canoas: Editora La Salle, 1980.

DESAULNIERS, Julieta B. Ramos. A formação via impresso. In: CATANI, Denice Bárbara; BASTOS, Maria Helena Câmara. Educação em revista: a imprensa periódica e a história da educação. São Paulo: Escrituras, 1997. p. 127-154.

DO Ó, Jorge Ramos. O governo de si mesmo: modernidade pedagógica e encenações disciplinares do aluno liceal (último quartel do século XIX - meados do século XX). Lisboa: Educa, 2003.

MENNUCCI, Sud. A crise de educação. 2. ed. São Paulo: Editora Piratininga, 1934. NÓVOA, Antonio A imprensa de educação e ensino. In: CATANI, Denice Bárbara; BASTOS, Maria Helena Câmara. Educação em revista: a imprensa periódica e a história da educação. São Paulo: Escrituras, 1997. p. 11-32.

PINEDA, Silvana Schuler. Hyloea: o feminino na revista dos alunos do Colégio Militar de Porto Alegre (1922-1938). Dissertação (Mestrado em Educação). Porto Alegre, Faculdade de Educação, UFRGS, 2003.

PRADO, Adonia Antunes. Intelectuais e educação no Estado Novo (1937-1945): o debate sobre a formação do professor primário rural. Teias, Rio de Janeiro, ano 1, n. 1, p. 46-55, jan./jun. 2000.

PRADO, Adonia Antunes. Ruralismo pedagógico no Brasil do Estado Novo. Estudos Sociedade e Agricultura, Rio de Janeiro, n. 4, p. 5-27, 1995. 
SOUSA, Cynthia Pereira de. A educação pelas leituras: registros de uma revista escolar (1930-1960). In: CATANI, Denice Bárbara; BASTOS, Maria Helena Câmara. Educação em revista: a imprensa periódica e a história da educação. São Paulo: Escrituras, 1997. p. 93-110.

WERLE, Flávia Obino Corrêa. Escola Normal Rural no Rio Grande do Sul: história institucional. Revista Diálogo Educacional, v. 5, n. 14, p. 35-50, jan./abr.2005.

Recebido em: 20/06/06

Aprovado em: $12 / 03 / 07$ 